\title{
BACTERIOLOGICAL PROFILE AND ANTIMICROBIAL RESISTANCE PATTERNS ISOLATES IN PUS SAMPLES AT AGARTALA GOVERNMENT MEDICAL COLLEGE
}

\author{
ARUNDHATI JAMATIA ${ }^{1}$, DEBASISH ROY ${ }^{1}$, RUBIN SHIL ${ }^{2}$, PRANAV KUMAR PRABHAKAR ${ }^{2 *}$ \\ ${ }^{1}$ Department of Microbiology, Agartala Government Medical College, Agartala, Tripura, India, ${ }^{2}$ Department of Medical Laboratory Science, \\ Lovely Professional University, Phagwara, Punjab, India. Email: pranav.16113@lpu.co.in
}

Received: 27 September 2016, Revised and Accepted: 07 October 2016

\section{ABSTRACT}

Objective: Injudicious use of antibiotics in the management of pyogenic infections leads to emergence and spread of antibiotic resistance among pyogenic bacteria. This study aimed toward the determination of the bacterial isolates from pus samples and their antibiotic resistance pattern.

Methods: A retrospective analysis of 359 consecutive pus specimens received at Microbiology Department of Gobind Ballabh Pant Hospital under Agartala Government Medical College, Agartala has been done. Bacterial isolates were identified by standard microbial techniques, and antibiotic susceptibility was done by modified Kirby-Bauer methods.

Results: Growth was seen in 176 (49.02\%) specimens out of 359 samples. A total of 176 specimens yielded single isolate whereas 4 specimens yielded 2 isolates. Staphylococcus aureus was the most common organism isolated 53 (30.11\%) followed by Pseudomonas spp. 37 (21.02\%), Klebsiella spp. 30 (17.07\%), Escherichia coli 24 (13.63\%) Proteus spp. 11 (6.40\%), Acinetobacter spp. 7 (3.97\%), Citrobacter spp., and Enterobacter spp. $4(2.27 \%)$ each. The highest number of multidrugs resistant isolates was Klebsiella spp. All S. aureus were $100 \%$ sensitive to vancomycin, and all Gram-negative bacilli were $100 \%$ to sensitive to imipenem and amikacin.

Conclusion: This study revealed the most common organism in pus samples is $S$. aureus followed by Pseudomonas spp. and highly multidrug resistance Klebsiella spp. Hence, continued monitoring of susceptibility pattern need to be carried out to detect the true burden of antibiotic resistance in organism and prevent their further emergence by judicious use of drugs.

Keywords: Pyogenic bacteria, Antibiotic resistance, Multidrug-resistant Klebsiella, Antibiotic policy.

(c) 2017 The Authors. Published by Innovare Academic Sciences Pvt Ltd. This is an open access article under the CC BY license (http://creativecommons. org/licenses/by/4. 0/) DOI: http://dx.doi.org/10.22159/ajpcr.2017.v10i1.15411

\section{INTRODUCTION}

The pyogenic infections are either polymicrobial or monomicrobial with an average of 5-6 organisms is often involved in the infections with mixture of aerobic and anaerobic organisms [1]. The most common organism likely to be encountered from pus are Gram-positive cocci such as Staphylococcus aureus, Staphylococcus epidermidis followed by Gramnegative bacilli, such as Klebsiella spp., Pseudomonas spp., Escherichia coli, Proteus spp., Citrobacter spp., Acinetobacter spp., and Enterobacter spp., respectively [2]. These are the type of infections require wise choice of antimicrobial treatment which should be based on cultured organisms and their susceptibility pattern as dilemma of starting empirical therapy with narrow spectrum agent or broad spectrum agent or one that comes resistant organism to persist [3]. However, the type of causative organism for infections and their sensitivity and resistant pattern very from place to place. Hence, the appropriate selection of an effective antimicrobial agent for microbial infection requires knowledge of the potential microbial pathogen and understanding of the therapeutic agent [4]. Therefore, this retrospective study was carried out to investigate the bacterial isolates responsible for formation of pus and study their antimicrobial susceptibility pattern at Agartala Government Medical College, Gobindh Ballabh Pant Hospital (GBPH).

\section{METHODS}

A retrospective analysis of 359 consecutive pus specimens received at microbiology laboratory from various wards of Agartala Government Medical College and GBPH, Agartala over a period of 1 year from February 2013 to February 2014 were done. The aspirate specimens were transported in sterile leak-proof container, and swabs were obtained on sterile cotton swabs and were processed immediately in the laboratory. All specimens were inoculated onto nutrient agar, blood agar, and MacConkey agar (Hi Media) incubated overnight at $37^{\circ} \mathrm{C}$. Bacterial isolates were identified based on colony morphology, grams stain, and conventional biological tests following standard microbial techniques. Antibiotics susceptibility testing was done using Mueller Hinton agar (Hi-Media) by modified Kirby-Bauer methods as recommended by CLSI.

\section{RESULTS}

A total of 359 samples were received at the laboratory during the study period. The highest number of samples received from the Department of Orthopedics, 203 followed by Surgery 90, ENT 26, Obstetrics and Gynecology 17, and skin 10. Out of 359 samples, 176 samples showed growth of organism comprising $49.02 \%$ while 183 samples did not show any growth comprising $50.97 \%$. Table 1 shows ward-wise distribution of samples.

Mixed growth was seen in four samples and 176 samples showed single growth. The most common isolates were $S$. aureus 53/176 comprising $30.11 \%$ followed by Pseudomonas aeruginosa 37/176 (21.02\%), Klebsiella spp. 30/176 (17.03\%), E. coli 24/176 (13.63\%), Proteus spp. $11 / 176$ (6.25\%), 7/176 (3.37\%), Citrobacter spp., and Enterobacter spp. 6/176 (3.34\%) each (Table 2).

All the isolates of $S$. aureus were sensitive to vancomycin. $66.66 \%$ isolates of $S$. aureus were sensitive to cloxacillin, $56.25 \%$ to amoxiclav, $54.71 \%$ to Erythromycin, $40.00 \%$ to Cefodoxime and $52.63 \%$ to Moxifloxacin (Table 3). 
All isolates were vancomycin sensitive. The Higher rate of resistance was seen against penicillin (84.32\%) and amoxicillin (62.50\%). All the isolates of $E$. coli were sensitive to amikacin followed by $70.56 \%$ to ceftazidime clavulanic acid, $70 \%$ to gentamicin, $66.66 \%$ to ofloxacin. Nearly, $75 \%$ of the E. coli were resistant to ceftazidime followed by

Table 1: Ward-wise distribution of samples

\begin{tabular}{llll}
\hline Ward & Male & Female & Total \\
\hline Orthopedic & 157 & 46 & 203 \\
Surgery & 36 & 54 & 90 \\
ENT & 18 & 8 & 26 \\
O/G & & 17 & 17 \\
Skin & 7 & 3 & 10 \\
Medicine & 3 & 1 & 4 \\
Mental & 2 & & 2 \\
Cancer & 1 & 1 & 2 \\
Cabin & 2 & & 2 \\
Anesthesia & 1 & & 1 \\
Dental & 1 & & 1 \\
Pediatric & 1 & 130 & 1 \\
Total & 229 & & 359 \\
\hline
\end{tabular}

Table 2: Bacterial growth profile of pus culture

\begin{tabular}{ll}
\hline Organism isolated & Total (\%) \\
\hline S. aureus & $53(30.11)$ \\
P. aeruginosa & $37(21.02)$ \\
E. coli & $24(13.63)$ \\
Klebsiella spp. & $30(17.05)$ \\
Proteus spp. & $11(6.25)$ \\
Acinetobacter spp. & $7(3.97)$ \\
Citrobacter spp. & $6(3.40)$ \\
Enterbacter spp. & $4(2.27)$ \\
Yeast cell & $4(2.27)$ \\
Total & $176(176 / 100)$ \\
\hline
\end{tabular}

S. aureus: Staphylococcus aureus, P. aeruginosa: Pseudomonas aeruginosa,

E. coli: Escherichia coli

Table 3: Sensitivity and resistant pattern of S. aureus

\begin{tabular}{lll}
\hline Type of antibiotic & $\begin{array}{l}\text { Percentage } \\
\text { of sensitive }\end{array}$ & $\begin{array}{l}\text { Percentage } \\
\text { of resistant }\end{array}$ \\
\hline Erythromycin & 54.71 & 45.29 \\
Amoxicillin & 37.5 & 62.50 \\
Azithromycin & 51.02 & 48.98 \\
Penicillin & 15.68 & 84.32 \\
Amoxiclav & 56.25 & 43.75 \\
Cloxacillin & 66.66 & 33.34 \\
Cefodoxime & 40.00 & 60.00 \\
Moxifloxacin & 52.63 & 47.37 \\
\hline
\end{tabular}

S. aureus: Staphylococcus aureus
$58.34 \%$ to cefotaxime and $56.85 \%$ to ceftriaxone, and $56.85 \%$ were extended-spectrum beta-lactamase (ESBL) producers E. coli. A total of 10 isolates of $E$. coli shows resistant to all drugs except imipenem. All the isolates of Pseudomonas spp. were $100 \%$ sensitive to imipenem and amikacin. Nearly $70 \%$ of Pseudomonas isolates showed sensitivity to gentamicin and cefotaxime and $68.42 \%$ isolates showed sensitivity to ceftazidime clavulanic acid. These isolates showed $100 \%$ resistant to ampicillin, penicillin, and cloxacillin. $30 \%$ of the Pseudomonas isolates are ESBL producers. Higher rate of multidrugs resistant strain was seen among isolates of Klebsiella spp. $50 \%$ of the isolates were showed all drugs resistant pattern except with imipenem. $80 \%$ of isolates were sensitive to moxifloxacin followed by $57.14 \%$ to amikacin. $55.56 \%$ isolates were ESBL producers. Isolates showed $100 \%$ resistant to amoxiclavulanic acid, amoxicillin, and penicillin. $80 \%$ of the isolates were resistant to ceftazidime. All the isolates of Acinetobacter spp. were sensitive to amikacin and imipenem. 50\% isolates were ESBL producers, and all were resistant to amoxi clavulanic acid and cotrimoxazole. Isolates of Proteus and Citrobacter spp. were 100\% sensitive to moxifloxacin and amikacin. $11.12 \%$ of Proteus spp. and $20.00 \%$ of Citrobacter were ESBL producers. Table 4 shows resistant pattern of Gram-negative bacilli.

\section{DISCUSSION}

Good similarity is observed in the present study with other studies reported by various authors across the country.

In present study culture, the positive rate is $49.02 \%$ which is slightly high compared to overall incidence of wound sepsis in India range from $10 \%$ to $33 \%$. The Western studies indicate this range to be between $3 \%$ and $10 \%$, with average of $5 \%$. Predominant isolates were S. aureus highest followed by Pseudomonas spp., Klebsiella spp., E. coli, Proteus spp., and Acinetobacter spp. where similar findings observed in the studies by Rajan [5], Marton and Nichols [6] and Sader et al. [7].

Among S. aureus isolates penicillin, amoxicillin, and cefotaxime resistance were higher as similar to the study conducted by Tiwari and Kaur [8]. In our study, erythromycin resistance was found $45.29 \%$ which is comparatively low than that was found by Tiwari and Kaur [8]. There is a higher prevalence of methicillin-resistant $S$. aureus at our hospital. This may be the reason for occurrence of higher resistance toward beta-lactam and the other group of drugs. All S. aureus isolates were $100 \%$ sensitive to vancomycin.

In the present study, Pseudomonas aeruginosa, Klebsiella spp., and E. coli were the most common Gram-negative bacilli obtained from the pus. A number of study has also come to same conclusion and reported in that same order regarding occurrence of pathogens in wound infections [9-11]. Among Gram-negative bacilli, highest resistance was seen with amoxiclavulanic acid (100\%), amoxicillin (100\%), and penicillin (100\%). Resistance toward the third generation cephalosporin was also high such as cefotaxime, ceftriaxone and ceftazidime, and cefotaxime. This may be because of increasing expression of ESBL

Table 4: Antibiotic resistance pattern of Gram-negative bacilli

\begin{tabular}{|c|c|c|c|c|c|c|}
\hline Antibiotic & E. $\operatorname{coli}(\%)$ & $\begin{array}{l}\text { Klebsiella spp. } \\
(\%)\end{array}$ & Pseudomonas (\%) & $\begin{array}{l}\text { Proteus spp. } \\
(\%)\end{array}$ & $\begin{array}{l}\text { Citrobacterspp. } \\
(\%)\end{array}$ & $\begin{array}{l}\text { Acinetobacter spp. } \\
(\%)\end{array}$ \\
\hline Cetriaxone & 56.85 & 62.5 & 41.18 & 11.12 & 40 & 50 \\
\hline Cefotaxime & 58.34 & 55.56 & 30 & 22.23 & 20 & 50 \\
\hline Ceftazidime clavulanic acid & 29.42 & 72.73 & 31.58 & 20 & 71.73 & ND \\
\hline Amoxiclavulanic acid & 100 & 100 & 95 & 80 & 100 & 100 \\
\hline Cotrimoxazole & ND & 55.56 & 88.88 & 77.78 & ND & 100 \\
\hline Ofloxacin & ND & ND & 66.67 & ND & ND & ND \\
\hline Amikacin & 00.00 & 42.86 & 00.00 & 50 & 00.00 & 00.00 \\
\hline Penicillin & 100 & 100 & 100 & ND & ND & 100 \\
\hline Amoxicillin & 100 & 100 & 100 & ND & ND & 100 \\
\hline
\end{tabular}

E. coli: Escherichia coli 
among Gram-negative bacilli. 22.72\% of isolates showed resistance to all drugs tested without imipenem. Klebsiella isolates contributed maximum number of multidrug resistance. Ceftriaxone and cefotaxime were the drugs with $37.5 \%$, and $44.44 \%$ isolates sensitive in this group followed by ceftazidime and gentamicin.

\section{CONCLUSION}

This study reports the most common organism encountered in pus is S. aureus followed by Pseudomonas aeruginosa, Klebsiella spp., and E. coli. Vancomycin, aminoglycosides such as amikacin and gentamicin and imipenem could be used as empirical therapy to cover these organisms. Hence, continued monitoring of susceptibility pattern needs to be carried out to detect the true burden of antibiotic resistance in organism and prevent their further emergence by judicious use of drugs.

\section{REFERENCES}

1. Jeffrey Stone A and Paul Cianci. Diabetic wounds. Diabetes Spectr 1997;4(2):118-23

2. Krige JE, Beckingham JI. Liver abscesses and hydatid disease. $\mathrm{Br}$ Med J 2001;322:537.

3. Shea KW. Antimicrobial therapy for diabetic foot infections. A practical approach. Postgrad Med 1999;106(1):85-6, 89-94.

4. Agnihottri N, Gupta V, and Joshi RM. Aerobic bacterial isolates from burn wound infections and their Antibiograms - A five-years study. Burns 2004;30(3):241-3

5. Rajan S. Skin and soft-tissue infections: Classifying and treating a spectrum. Cleve Clin J Med 2012;79(1):57-66.

6. Marton WJ, Nichols RL. Recognition, prevention, surveillance, and management of surgical site infections: Introduction to the problem and symposium overview. Clin Infect Dis 2001;33 Suppl 2:S67-8.

7. Sader HS, Jones RN, Silva JB; SENTRY Participants Group (Latin America). Skin and soft tissue infections in Latin American medical centers: Four-year assessment of the pathogen frequency and antimicrobial susceptibility patterns. Diagn Microbiol Infect Dis 2002;44(3):281-8

8. Tiwari P, Kaur S. Profile and sensitivity pattern of bacteria isolated from various cultures in a Tertiary Care Hospital in Delhi. Indian J Public Health 2010;54(4):213-5.

9. Ghosh A, Karmakar PS, Pal J, Chakraborty N, Debnath NB, Mukherjee JD. Bacterial incidence and antibiotic sensitivity pattern in moderate and severe infections hospital patients. J Indian Med Assoc 2011;107(1):21-2, 24-5.

10. Zubair M, Malik A, Ahmad J. Clinico-microbiological study and antimicrobial drug resistance profile of diabetic foot infections in North India. Foot (Edinb) 2011;21(1):6-14

11. Basu S, Ramchuran Panray T, Bali Singh T, Gulati AK, Shukla VK. A prospective, descriptive study to identify the microbiological profile of chronic wounds in outpatients. Ostomy Wound Manage 2009;55(1):14-20. 